\title{
O Papel do Ministério Público na Efetivação do Direito à Convivência Familiar e Comunitária de Crianças e Adolescentes ${ }^{1}$
}

Débora Tomé de Sousa² Dairton Costa de Oliveira ${ }^{3}$ Raquel Coelho de Freitas ${ }^{4}$

\section{RESUMO}

direito à convivência familiar e comunitária de crianças e adolescentes encontra previsão legal em normas e princípios constitucionais, este direito tem como fundamento material o princípio da Proteção Integral, que só se mostrará atingido, quando garantido ao infante seu desenvolvimento físico, mental e social em ambiente familiar adequado. Desse modo, cabe ao Ministério Público, em prisma constitucional, a função de defesa dos interesses sociais e individuais indisponíveis, nestes se encaixando a defesa do direito de crianças e adolescentes à convivência familiar e comunitária. Para garantia desse direito específico, o Ministério Público pode agir em nome próprio, como substituto processual, tendo a atribuição, por ser órgão de responsabilização, de ajuizar Medidas Protetivas, Ações Civis Coletiva ou Individual e a Ação de Destituição do Poder Familiar. Ressalta-se que não apenas os pais, ou os responsáveis, devem ser sujeitos de responsabilização pelo órgão ministerial, o

1 Data de recebimento: 17/07/2018. Data de aceite: 21/09/2018.

2 Mestranda em Direito pela Universidade Federal do Ceará. Promotora Acadêmica da Infância em Fortaleza-Ceará. E-mail: deboratomedesousa@gmail.com

3 Promotor de Justiça. Especialista Interdisciplinar em Direito da Criança e do Adolescente. E-mail: dairton35@yahoo.com.br

4 Doutora em Direito pela Universidade Federal do Rio de Janeiro. Professora da Universidade Federal do Ceará. E-mail: rclcesar@gmail.com 
Estado, por seus diversos entes, que é solidariamente responsável pela proteção dos direitos das crianças e dos adolescentes, tem-se mostrado vilipendiador desses direitos, quando não garante ao infante em proteção uma resposta útil em tempo razoável de duração de seu processo. Neste sentido, o objetivo do artigo é apresentar as medidas e ações de atribuição do Ministério Público que podem efetivar o direito à convivência familiar e comunitária de crianças e adolescentes em situação de institucionalização.

Palavras-chave: Ministério Público. Crianças e Adolescentes. Direito à Convivência Familiar e Comunitária.

\section{INTRODUÇÃO}

Com a promulgação da Constituição Federal em 1988, o Brasil deu início formal à era da Doutrina da Proteção Integral em superação à era da Doutrina Menorista. Crianças e adolescentes, que antes eram considerados "objeto" de direito dos adultos, como se consubstanciassem um "patrimônio de sangue" de seus pais biológicos, passaram a ser considerados "sujeitos de direitos", aos quais se reconheceram, constitucionalmente, todos os direitos que já eram de titularidade dos adultos e outros direitos fundamentais exclusivos, ou melhor, específicos e com prioridade absoluta sobre os de outrem, dentre eles, os de adultos, pais biológicos ou terceiros interessados, em conflitos eventuais, em razão de serem pessoas em condição peculiar de desenvolvimento.

Nesse contexto, um dos direitos fundamentais específicos reconhecidos a esses indivíduos é o direito à convivência familiar e comunitária, o qual expressa a relevância da família e da comunidade para o sadio desenvolvimento físico, mental e social de crianças e adolescentes.

Em 1990, atendendo a determinação constitucional que obrigava 
o legislador ordinário a dispor sobre a Doutrina da Proteção Integral em todos os seus termos e nuances, editou-se o Estatuto da Criança e do Adolescente, que dentre inúmeros princípios, direitos materiais e processuais, disciplinou em seu Título II, capítulo III, o direito à convivência familiar e comunitária, estabelecendo ainda como dever da família, da comunidade e do Estado, este a partir da corresponsabilidade dos três entes federados, a garantia desse direito específico, conforme consta também na Constituição Federal.

Ao Ministério Público, cuja autonomia funcional nasceu em conjunto com a doutrina da proteção integral, coube a importante função constitucional de defender os interesses sociais e individuais indisponíveis, nestes se encaixando os direitos de crianças e adolescentes, sendo dele a atribuição de ajuizar medidas protetivas em favor de crianças e adolescentes, medidas de responsabilização dos pais ou responsáveis, ações civis públicas - visando à promoção e efetivação de direitos individuais e coletivos - e a ação de destituição e suspensão do poder familiar em graves de necessária intervenção provisória ou definitiva do Estado sobre o poder familiar, conforme previsões legais do ECA, Código de Processo Civil e Lei de Ação Civil Pública.

Para se verificar toda a sorte de ações e possibilidades de atuação do Ministério Público na defesa e promoção dos direitos de crianças e adolescentes, afastados de sua família de origem à convivência familiar e comunitária, utilizou como método científico tanto a pesquisa bibliográfica, com auxílio de doutrina especializada como Maria Regina Fay de Azambuja e Ângela Pinheiro, quanto a pesquisa documental a partir de registro de distribuição de ações ajuizadas pelo Ministério Público da Infância e Juventude de Fortaleza, destinadas a promover esse direito específico.

No primeiro tópico será abordado o direito à convivência familiar e comunitária das crianças e adolescentes. Já no segundo tópico, será apresentado o papel do Ministério Público como garantidor desses 
e de outros direitos fundamentais das crianças e dos adolescentes. Por fim, no terceiro tópico, serão apresentadas as ações judiciais de atribuição do Ministério Público que visam efetivar o direito à convivência familiar e comunitária de crianças e adolescentes em situação de institucionalização.

Com o estudo verificou-se que o Ministério Público tem importante função na efetivação do direito à convivência familiar e comunitária, garantindo que as crianças e os adolescentes afastados de sua família de origem, em virtude de violação de direitos, possam ter suas situações resolvidas no tempo razoável previsto em lei, e para que haja a devida responsabilização dos atores envolvidos nos casos concretos como pais, responsáveis, sociedade e Estado.

\section{O DIREITO FUNDAMENTAL À CONVIVÊNCIA FAMILIAR E COMUNITÁRIA}

A Constituição Federal de 1988 foi responsável pela mudança de paradigma com relação ao tratamento despendido às crianças e aos adolescentes, uma vez que ao adotar a doutrina da proteção integral, estes indivíduos passaram a ser considerados sujeitos de direitos, sendo titulares de direitos fundamentais igualmente aos adultos, podendo exigi-los em face dos demais particulares e do Estado (PINHEIRO, 2004, p. 351).

Nesse contexto, pelo fato de serem pessoas em condição peculiar de desenvolvimento, as quais necessitam de proteção especial e integral para a garantia e efetivação de seus direitos, a Constituição Federal reconheceu-lhes, ainda, direitos fundamentais específicos, ou seja, exclusivos, de modo a favorecer o seu pleno e sadio desenvolvimento (ROSSATO; LEPORE; CUNHA, 2017, p. 61). Deste modo, um desses direitos específicos é o direito fundamental à convivência familiar e comunitária, o qual está previsto no artigo 227, da Constituição Federal de 19885.

5 Ressalta-se que o direito à convivência familiar e comunitária de crianças e adolescentes também 
Corroborando com a norma constitucional, o Estatuto protetivo ratifica, em suas disposições preliminares e fundamentais, que crianças e adolescentes possuem o direito de crescerem e se desenvolverem em ambiente familiar, o qual a neurociência já demonstrou ser o melhor local para que os indivíduos possam desenvolver suas potencialidades, relacionarem-se com afeto, amor e segurança, sendo ambiente de formação do caráter com base em valores morais e éticos (O Começo da Vida, O Filme 2016).

Esta convivência familiar deve estar atrelada à convivência comunitária, que se relaciona com o fato de crianças e adolescentes participarem da vida social, seja na escola, no lazer, no acesso à saúde e, principalmente, participando das decisões políticas das quais são destinatários, exercendo suas cidadanias. Assim sendo, em razão da imprescindibilidade da família e da comunidade no desenvolvimento dos sujeitos, Maria Regina Fay de Azambuja afirma que o direito à convivência familiar e comunitária "integra a condição humana" dos indivíduos, não podendo ser negligenciado ou menosprezado (2006, p. 428).

O Estatuto da Criança e do Adolescente, Lei no 8.069/90, teve a importante missão de regular o direito à convivência familiar e comunitária, e fez isto de forma bastante coerente com os princípios da doutrina da proteção integral e da absoluta prioridade. Neste sentido, o ECA dedicou o Capítulo III "Do direito à convivência familiar e comunitária", do Título II "Dos direitos fundamentais", inteiramente para normatizar as diversas situações que envolvem o direito à convivência familiar e comunitária, observadas a relevância de tal direito fundamental para o desenvolvimento de crianças e adolescentes, e a necessidade de se buscar efetivar e promovê-lo.

Uma das previsões importantes trazidas pelo ECA diz respeito ao caráter excepcional e temporário das medidas protetivas, que

está previsto na Declaração de Direitos da Criança, adotada pela Organização das Nações Unidas em 1959 e na Convenção dos Direitos das Crianças de 1989, ambos os documentos internacionais foram ratificados pela República Federativa do Brasil e inspiraram a Constituição Federal de 1988. 
colocam a criança ou o adolescente em família substituta, em família acolhedora, ou em instituição de acolhimento, haja vista que é direito destes indivíduos serem criados e educados no seio de uma família, preferencialmente, de sua família de origem e, excepcionalmente, em família substituta, conforme caput do artigo 19, porém sempre se atentando para a existência de um ambiente familiar "adequado" ao seu desenvolvimento integral.

Nesse contexto, louvável foi a alteração promovida pela Lei $13.509 / 2017$ ao $\S 1^{\circ}$, do artigo 19, do ECA, que reduziu de seis para três meses o tempo de reavaliação da situação de crianças e adolescentes inseridas em programa de acolhimento institucional ou familiar, visando a fornecer dados sempre atualizados à autoridade judiciária, para que esta possa acompanhar de perto o fortalecimento de vínculos com a família ou, em caso de impossibilidade deste, que seja tomada uma atitude mais rápida, para que o direito à convivência familiar e comunitária dos acolhidos seja respeitado, e as crianças e adolescentes não permaneçam nos acolhimentos por mais de dezoito meses, nos moldes da também louvável alteração do $\S 2^{\circ}$, do mesmo artigo de lei, que reduziu para os referidos dezoito meses o prazo anterior máximo de dois anos de institucionalização.

O ECA afirma e apresenta algumas medidas que devem ser tomadas para garantia do direito à convivência familiar e comunitária de crianças e adolescentes, devendo inclusive esse direito ser respeitado pelas instituições de acolhimento, com relação aos indivíduos sob sua guarda e proteção, que vai desde a sua organização e estrutura, que deve ser semelhante a uma casa familiar, até o acompanhamento das famílias de origem de modo a favorecer o fortalecimento de vínculos "afetivos" familiares para o retorno dos acolhidos à família.

Portanto, são exemplos de medidas que privilegiam a convivência familiar e comunitária o fortalecimento de vínculos com a família de origem, por meio de medidas de apoio a essa família, que a ajudem a se organizar e reestruturar, fazendo cessar a causa 
que gerou o afastamento da criança ou do adolescente de seu seio; a colocação do infante afastado em família extensiva ou ampliada, a partir da certificação de existência pretérita de vínculos de convivência, afetividade e afinidade da criança ou adolescente para com seus parentes legais; guarda subsidiada; colocação em família substituta, mediante guarda excepcional, tutela ou adoção; colocação em programa de acolhimento familiar e, por fim, participação em programa de apadrinhamento.

Estudar, capacitar-se e desenvolver propriedade de conhecimento sobre o processo e a essência de todas essas possibilidades citadas de efetivação do direito à convivência familiar e comunitária, para crianças e adolescentes em situação de institucionalização, é o papel do agente Ministerial que labuta na área protetiva, disponibilizando-lhe a lei toda uma sorte de atos jurídicos e políticos capazes de promover e garantir esse direito, com prazos processuais e materiais bem distintos, estabelecidos em favor dos infantes institucionalizados, e que precisam ser respeitados pelo sistema de justiça, sob pena de se estar tratando esses "sujeitos de direito" como "objetos de direito" de adultos, que se mostram familiarmente negligentes e, muitas vezes, a própria fonte de violação do direito ao desenvolvimento sadio da criança ou adolescente em proteção.

\section{A FUNÇÃO DO MINISTÉRIO PÚBLICO COMO GARANTIDOR DE DIREITOS DAS CRIANÇAS E ADOLESCENTES}

A Constituição Federal de 1988 positivou, com autonomia orgânica em suas diretrizes, a criação de diversas instituições com funções essenciais à justiça e ao exercício pleno da cidadania por cada integrante do povo, dentre elas o Ministério Público. De acordo com referida codificação, artigo 127, ao Ministério Público incumbe a defesa dos interesses sociais e individuais indisponíveis, ou seja, a proteção aos direitos fundamentais individuais ou coletivos. 
Nesse contexto, é atribuição constitucional do Ministério Público a defesa dos direitos e garantias das crianças e adolescentes, uma vez que os direitos destes, por serem pessoas em condição peculiar de desenvolvimento, são individuais indisponíveis (DI MAURO, 2017, p. 115).

Além disso, a Lei no 8.625, a qual institui a Lei Orgânica Nacional do Ministério Público, em seu artigo 25, expressa diversas funções que o órgão possui com relação aos direitos de crianças e adolescentes, como promover o inquérito civil e a ação civil pública para proteção, prevenção e reparação dos direitos difusos, coletivos, individuais indisponíveis e homogêneos, e exercer a fiscalização de estabelecimentos de acolhimento de crianças e adolescentes.

Verifica-se, portanto, que além do Ministério Público poder ajuizar ações civis públicas em favor dos interesses difusos, coletivos, individuais indisponíveis e homogêneos de titularidade de crianças e adolescentes, ele pode investigar, por meio do procedimento de inquérito civil, e deve fiscalizar as instituições de acolhimento institucional, cabendo-lhe, por substituição processual, a titularidade para exigir e reivindicar tais direitos, falando em nome próprio, pelos "infans" em proteção, tendo em vista a falta de representação, ou incapacidade legal, de tais indivíduos para o exercício regular ou para busca judicial de seus direitos em violação.

Nesse sentido, observa-se que a Lei Complementar n 75/93, a qual versa sobre a organização e atribuição do Ministério Público, foi mais específica ao regular a atribuição do órgão ministerial na defesa dos direitos dos citados indivíduos, conforme artigo 6 $6^{\circ}$, VII, " $\mathrm{C}^{\prime}$ :

\footnotetext{
Art. $6^{\circ}$. Compete ao Ministério Público da União:

[...]

VII - promover o inquérito civil e a ação civil pública para:

c) a proteção dos interesses individuais indisponíveis, difusos e coletivos, relativos às comunidades indígenas, à família, à criança, ao adolescente, ao idoso, às minorias étnicas e ao consumidor;
} 
Ademais, no que tange à atuação do Ministério Público na proteção e promoção do direito à convivência familiar e comunitária de crianças e adolescentes, o Estatuto da Criança e do Adolescente, Lei no 8.069/90, estabelece, no seu artigo 88, VI, como diretriz de atendimento, a integração entre os diversos atores de proteção, incluindo o Ministério Público, Poder Judiciário, Defensoria Pública, Conselho Tutelar e outros, para agilizar o atendimento de crianças e adolescentes inseridos em programas de acolhimento institucional ou familiar, visando à rápida reintegração à família de origem ou a colocação em família substituta.

Ressalta-se, ainda, que o ECA em seu artigo 201, III, previu que cabe ao Ministério Público ajuizar ação de destituição de poder familiar nos casos de impossibilidade de retorno da criança ou do adolescente acolhido à sua família de origem, ou sua inserção em família extensa, acolhedora ou substituta mediante guarda. A ação de destituição do poder familiar visa a oportunizar a inserção de criança ou adolescente no cadastro de adoção, possibilitando que ela possa ser adotada, e possa conviver no ambiente familiar saudável e apropriado ao seu desenvolvimento pleno.

Ademais, o Ministério Público é um dos órgãos que possui acesso ao cadastro, mantido pela autoridade judiciária, referente a crianças e adolescentes inseridos em programas de acolhimento familiar ou institucional, devendo se verificar, regularmente, se nele constam as informações atualizadas acerca da situação jurídica de crianças e adolescentes, com o escopo de acompanhar e tomar as providências necessárias para a reintegração familiar ou colocação em família substituta, em privilégio ao direito à convivência familiar e comuni-

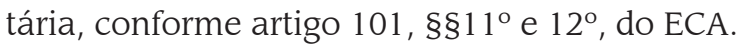

Percebe-se, portanto, que as ações do Ministério Público orientadas à proteção dos direitos e garantias de crianças e adolescentes possuem respaldo constitucional e infraconstitucional, não podendo tal órgão se eximir de suas funções sem que cause prejuízos a estes 
indivíduos, que não conseguem sozinhos reivindicar seus direitos, influenciar a agenda política por mais políticas públicas voltadas a eles, e responsabilizar quem acabe por violar seus direitos fundamentais, constando entre estes atores de violação principalmente os entes estatais (município, estado e união), quando se omitem na construção de políticas e serviços públicos expressos no ECA como formas de garantia de direitos.

\section{AÇÕES DO MINISTÉRIO PÚBLICO QUE EFETIVAM O DIREITO À CONVIVÊNCIA FAMILIAR E COMUNITÁRIA}

O Ministério Público possui a relevante função de defender os direitos das crianças e dos adolescentes. Nesse contexto, foi dito, no tópico anterior, que ele detém legitimidade para ajuizar, em nome próprio, medidas protetivas diversas, dentre elas, as de acolhimento familiar e institucional, a ação civil pública, e as ações de suspensão e de destituição do poder familiar, além de quaisquer ações ordinárias que visem garantir tais direitos. Tais ações são de uso recorrente do cotidiano jurídico ministerial da infância em que se verificam ocorrer múltiplas violações de direitos de crianças e adolescentes, dentre elas, a negligencia alimentar, higiênica, de cuidados de saúde, o abandono intelectual, material, afetivo e/ou a violência, que podem acontecer ou não, dentro do ambiente familiar, sendo, por vezes, necessário que a criança ou adolescente em proteção seja afastada desse convívio familiar que se mostra nocivo ou inadequado ao seu desenvolvimento sadio.

Verifica-se, porém, que a atribuição de promover e efetivar tais direitos, em especial, o direito à convivência familiar, não é apenas do Ministério Público, mas de toda a rede de proteção e atendimento, a qual envolve o Poder Judiciário, Defensoria Pública, Conselho Tutelar, Poder Executivo e sociedade civil organizada, por meio das instituições de acolhimento privadas (SILVA; MELLO; AQUINO, 2004, p. 1). 
Nesse contexto, age o Ministério Público como órgão de fiscalização e responsabilização, em essência, sendo essa sua natureza constitucional, destinando o órgão judiciário ao controle do mérito dos pedidos principais e cautelares, bem como das expedições das ordens de cumprimentos de sentenças e decisões; cabendo ao executivo a realização e construção das políticas públicas e serviços necessários ao gozo e garantia dos direitos buscados; o órgão tutelar a ação preventiva de ponta, agindo como os olhos, braços e pernas do sistema protetivo; o órgão defensorial com a assistência judiciária das famílias necessitadas, agindo, assim, na defesa dos interesses dos adultos necessitados, quando em contraposição com os dos infantes em proteção; e a sociedade civil organizada age na completação e corresponsabilidade político-seletiva de implemento de políticas públicas para o cumprimento do dever social que todos temos de cuidar dos nossos jovens, futuro e maior tesouro do país.

Assim, ao agir o Ministério Público, parte-se do primado de que a criança ou adolescente teve seu direito violado por ação ou omissão da sociedade, do Estado ou dos pais e responsáveis, e por isso merece ser protegida, sendo preferidas aquelas ações e medidas que visem ao fortalecimento de vínculos familiares e comunitários, e os agentes da violação precisam ser responsabilizados (BORDALLO, 2016, p. 594).

Desse modo, de acordo com o ECA artigo 101, § $2^{\circ}$, cabe ao referido órgão ajuizar as medidas de acolhimento institucional, em razão de grave violação de direitos, como abuso sexual ou violência, tal medida é excepcional e provisória, e visa à proteção da criança ou adolescente, enquanto sua família se reestrutura para reintegrá-la, ou para colocação em família substituta.

Por sua vez, a ação de destituição de poder familiar (DPF) pode ser ajuizada pelo Ministério Público, nos termos do artigo 155, do ECA, sendo necessária, quando não há possibilidade de reintegração de criança ou adolescente acolhido a sua família de origem ou extensa (DI MAURO, 2017, p. 106). Tal ação tem como propósito destituir os 
pais do poder familiar, e possibilitar a inclusão de criança ou adolescente no cadastro de adoção, para colocação em família substituta, e assim favorecer o direito à convivência familiar e comunitária.

Ressalta-se que o legislador, diante de uma violação grave, fundamento das ações de DPF, estabeleceu em no máximo 120 (cento e vinte) dias o prazo para conclusão da referida ação, nos moldes do artigo 163, caput, do ECA, privilegiando, assim, o direito do infante a uma família que não lhe viole direitos, e não o direito de seus familiares ao exercício do poder familiar sobre o infante, que teve seus direitos fundamentais gravemente violados.

Além das medidas citadas, contra os pais ou responsáveis, cabe ao Ministério Público ajuizar ações civis públicas individuais e coletivas em face do Município, tendo como objeto a responsabilização do ente federado em razão de sua conduta omissiva ou abusiva, no que tange às efetivação e garantia do direito à convivência familiar e comunitária de crianças e adolescentes afastados do convívio familiar. Nesse sentido, verifica-se que pode o parquet ajuizar ACP em face do Município, em virtude deste não manter acolhimentos institucionais em seu território, em quantidade e qualidade suficientes ao atendimento de sua demanda social, ocasionando o acolhimento de indivíduos em municípios diversos do domicílio de sua família de origem ou extensa, fato este que prejudica o fortalecimento de vínculos familiares diante da distância física, já que os familiares que ficam distantes do infante acolhido, geralmente não possuem ou recebem apoio que lhes propicie condições adequadas de visitar o infante, e as equipes dos acolhimentos também não fazem visitas ou outras intervenções técnicas em municípios diversos dos de suas jurisdições.

Ademais, é possível também o ajuizamento de ACP individual em face do Município com a finalidade indenizar criança ou adolescente pelo desrespeito ao seu direito à convivência familiar e comunitária, quando este fica em situação de institucionalização por tempo superior aos prazos legais estabelecidos em seu favor, sem uma resolução de sua situação por omissão ou demora por parte do Poder Público, 
conscientes as partes sobre os danos da permanência prolongada e injustificada de crianças e adolescentes em acolhimentos, o que, inclusive, lhes causa perda de oportunidades de viverem em famílias substitutas por adoção.

\section{CONSIDERAÇÕES FINAIS}

Concluiu-se pelo presente artigo que o direito à convivência familiar e comunitária de titularidade de toda criança e adolescente decorre da doutrina da proteção integral, e da constatação científica de que somente em uma família, e participando da comunidade, os indivíduos conseguem se desenvolver de forma plena e saudável, relacionando-se uns com os outros de forma afetuosa.

Além disso, verificou-se que o Ministério Público foi constitucional e infraconstitucionalmente incumbido das atribuições de defesa e promoção dos direitos indisponíveis de crianças e adolescentes, sendo o titular prioritário de ações de medidas protetivas, ações civis públicas e da ação de destituição do poder familiar, as quais visam de diferentes modos efetivar e garantir o direito à convivência familiar e comunitária.

Observou-se que o Ministério Público, por participar e fiscalizar a rede de proteção e atendimento, deve envidar esforços para ajuizar demandas com a finalidade de garantir direitos e cobrar, para que crianças e adolescentes acolhidas possam ter suas situações resolvidas no prazo legal previsto no ECA, produzindo ainda a devida responsabilização dos atores envolvidos nos casos, como pais ou responsáveis e, também, os entes federados, máxime o Município, uma vez que o prolongamento exagerado do período de acolhimento institucional, e o acolhimento em lugar diverso do domicílio da família acarreta a diminuição da possibilidade de retorno à família de origem ou extensa, por enfraquecimento dos vínculos e da perda da possibilidade de adoção, pelo avanço da idade. 


\section{THE ROLE OF THE BRAZILIAN PUBLIC PROSECUTION IN ENSURING THE RIGHT TO FAMILY AND COMMUNITY COEXISTENCE OF CHILDREN AND ADOLESCENTS}

\section{ABSTRACT}

The right to family and community coexistence of children and adolescents is legally established in constitutional norms and principles, this right is based on the principle of Integral Protection that will only be shown when guaranteed to the infant his physical, mental and social development in a family environment appropriate. In this way, it is the role of the Public Prosecution Service, in a constitutional prism, to defend social and individual interests that are unavailable, in which the defense of the right of children and adolescents to family and community coexistence. In order to guarantee this specific right, the Public Prosecution Service may act in its own name, as a procedural substitute, with the attribution, being the body responsible for filing protective measures, Collective or Individual Civil Actions and Action for Dismissal of Family Power. It should be stressed that not only the parents or guardians should be subject to responsibility by the ministerial body, the State, by its various entities, which is jointly responsible for the protection of the rights of children and adolescents, has been a vilification of these rights, when does not give the infant protection a useful response in a reasonable time for the duration of his or her process. In this sense, the objective of the article is to present the measures and actions of attribution of the Public Prosecutor that can effect the right to family and community coexistence of children and adolescents in a situation of institutionalization.

Keywords: Public Prosecutor's Office. Children and Adolescents. Right to Family and Community Living. 


\section{REFERÊNCIAS}

AZAMBUJA, Maria Regina Fay de. A violência sexual intrafamiliar: interfaces com a convivência familiar, a oitiva da criança e a prova da materialidade. Revista dos Tribunais, ano 95, v. 852, p. 424-446, set., 2006.

BORDALLO, Galdino Augusto Coelho. Ministério Público. In: Curso de direito da criança e do adolescente: aspectos teóricos e práticos. Kátia Regina Lobo Andrade Maciel (Coord.). 9. ed. São Paulo: Saraiva, 2016.

BRASIL. Constituição da República Federativa do Brasil de 1988. Disponível em: < http://www.planalto.gov.br/ccivil_03/constituicao/constituicaocompilado.htm> Acesso em: 29 jun. 2018.

BRASIL. Lei no 8069, de 13 de julho de 1990. Dispõe sobre o Estatuto da Criança e do Adolescente e dá outras providências. Disponível em:< http://www.planalto.gov.br/ccivil_03/leis/18069.htm> Acesso em 29 jun. 2018.

BRASIL. Lei Complementar n 73, de 20 de maio de 1993. Dispõe sobre a organização, as atribuições e o estatuto do Ministério Público da União. Disponível em: < http://www.planalto.gov.br/ccivil_03/leis/lcp/ lcp75.htm> Acesso em: 29 jun. 2018.

BRASIL. Lei n 8625, de 12 de fevereiro de 1993. Institui a Lei Orgânica Nacional do Ministério Público, dispõe sobre normas gerais para a organização do Ministério Público dos Estados e dá outras providências. Disponível em: < http://www.planalto.gov.br/ccivil_03/Leis/L8625. htm> Acesso em 29 jun. 2018.

BRASIL. Plano Nacional de Promoção, Proteção e Defesa do Direito de Crianças e Adolescentes à Convivência Familiar e Comunitária. Brasília: CONANDA; Conselho Nacional de Assistência Social; Presidência da República. Secretaria Especial dos Direitos Humanos, Ministério do Desenvolvimento Social e Combate à Fome, 2006.

DI MAURO, Renata Giovanoni. Procedimentos civis no estatuto da criança e do adolescente. 2. ed. São Paulo: Saraiva, 2017.

PINHEIRO, Ângela de Alencar Araripe. A criança e o adolescente, representações sociais e processo constituinte. Psicologia em Estudo, Maringá, v. 9, n. 3, p. 343-355, set./dez., 2004. Disponível em: <www.scielo. br/pdf/\%0D/ 
pe/v9n3/v9n3a02.pdf> Acesso em: 13 fev. 2018.

ROSSATO, Luciano; LÉPORE, Paulo Eduardo; CUNHA, Rogério Sanches. Estatuto da criança e do adolescente: comentado artigo por artigo. 9.ed. São Paulo: Saraiva, 2017.

SILVA, Enid Rocha de Andrade da; MELLO, Simone Gueresi; AQUINO, Luseni Maria Cordeiro de. Os abrigos para crianças e adolescentes e a promoção do direito à convivência familiar e comunitária. In: Enid Rocha de Andrade Silva (Coord.). O direito à convivência familiar e comunitária: os abrigos para crianças e adolescentes no Brasil. Brasília: IPEA, 2004. 